\title{
CONSTRUCTION OF PSEUDO CRS FRONTIER FOR A NEGATIVE DATA USING RTS MODEL OF ALLAHYAR \& A MODIFIED MULTIPLIER BCC MODEL
}

\author{
SUBHADIP SARKAR*
}

\begin{abstract}
Performance measurement of Decision Making Units (DMU) possessing an array of positive and negative type of input and output data has been an extensively researched topic in Data Envelopment Analysis. However, assessment of Returns to Scale (RTS) under negative data problem has only been attainable after the deliberation of a Variable Returns to Scale assumption. Steps referred earlier were indeed purported a solution around the vicinity of the Decision Making Unit under examination to predict the nature of the Returns to Scale of a firm. The extant investigation extends the research of Allahyar and Malkhalifeh [Comput. Ind. Eng. 82 (2015) 78-81] to identify a Pseudo Constant Returns to Scale Frontier for a negative data problem along with the new origin based on the provided data. However, this approach seems to be ineffective to create a frontier for multiple input output scenario. In this regard, a new variation of Multiplier form of BCC model is proposed here to detect the new origin for the sake of designing the Pseudo CRS frontier. Small examples are added for the elaboration of the CRS efficient DMUs using methods described by Allahyar and Malkhalifeh [Comput. Ind. Eng. 82 (2015) 78-81] to identify the new origin from the Multiplier form of BCC model. This outcome is finally validated with the aid of the multiplier model of Sahoo et al. [Eur. J. Oper. Res. 255 (2016) 545-558].
\end{abstract}

Mathematics Subject Classification. 90C08.

Received December 12, 2019. Accepted April 16, 2020.

\section{INTRODUCTION}

Returns to Scale has been a useful domain of research in the field of Micro-Economics to manifest the effects of long-term changes in the factor of production on the output set [21]. The tenet was found inevitable for assessing long-term average cost of a firm. In a nutshell, the prime focus of the study was whether factors were to be scaled up to achieve Economy of Scale due to Increasing Returns To Scale (RTS) or not so that long term average cost can be lowered further. In this regard, researchers conceived homogenous functions and transformation functions so that the effects on the output set could be tracked by estimating "Elasticity of Scale" [36]. These efforts acknowledged the presence of premeditated theoretical production frontier. However, techniques of measurement were required to be modified to reconcile with an empirical curve designated by Data Envelopment Analysis (DEA) [5, 15].

Keywords. Data Envelopment Analysis, negative data, constant return to scale.

Department of Management Studies, NIT Durgapur, Durgapur, West Bengal, India.

*Corresponding author: subhadip.sarkar@dms.nitdgp.ac.in 
The journey of Data Envelopment Analysis (DEA) commenced when the performance of students from participating and not participating schools were compared by Charnes et al. [9] by means of a data-oriented, linear programming-based, nonparametric approach described earlier by Farrell [18]. However, until the year of 1989, major theories alluded by Charnes et al. [9], Banker et al. [5], Brockett et al. [6] etc., in the arena of DEA, postulated the use of nonnegative data. Pastor [26] was the first who took the initiative for solving a negative data problem. He applied the theorems of "Translation Invariance" (originated by $[1,12]$ ) for measuring the performances of 23 bank branches. Moreover, he showed [27] that a Relocation of Origin, to another neighbouring point, does not alter the efficient frontier translation invariant DEA formulations. Thrall [37] however highlighted the impact of the translation invariant forms on the "optimal dual solutions". Halme et al. [19] recommended an interval variable with the subtraction of two ratio scale variables. An extra output (input) was created for each negative input scale (output) variable. Scheel [32], [13], later on, gave a similar treatment to non-positive input (output). An overview of the negative data problem can be seen in Pastor and Ruiz [28] as mentioned by Zhu and Cook in their book.

Although, the model could derive the radial efficiency scores but it failed to reflect the impact in terms of true production frontier. In this context, Emrouznejad and Anouze [13] proposed a unique way to measure the semi-oriented radial efficiency score. Any variable with mixed data was expressed in terms of the subtraction of two variables having nonnegative data. However, it could not ensure the Pareto Efficient Solution, but was able to handle a negative part of a variable in a positive format. Matin and Azizi [24] presented a two-phase approach based on a modified version of the classical additive DEA model, which was aimed to provide target with nonnegative value for each observed DMU.

Chambers et al. [7] explored a relationship among the distance function proposed by Shephard [35] and the Benefit function introduced by Luenberger [23]. These authors were able to express the later one as a directional distance input function for the characterization of a technology in terms of price and input space. In view of handling negative data, the directional distance model, prescribed by Chambers et al. [8], was applied by Portela et al. [29] for measuring performances of all branches of a Portuguese bank. This highly acclaimed Range Directional Model (RDM) is a unique variation of Relocation Policy. The efficiency of a firm is measured in comparison to the deviation seen from a pre-defined Ideal point (Superior Origin). The research of Cheng et al. [11] can be included under the category of Directional Distance Function which was able to achieve similar outputs as obtained from other radial models. The direction vector was kept proportional to the absolute value of the input-output vector of DMU.

Sharp et al. [34] introduced a modified slack-based model (MSBM) which was both unit invariant and translation invariant in nature. Negative data problem also had a unique problem of detecting the RTS for a Decision Making Unit under observation. RTS is measurement of increase in output bunch due to a unit increase in the input bunch. This would mean that if the input bunch is doubled then for a constant return to scale the output set also gets increased by two times. However, doubling a negative input along with another positive input do not mean in the same manner. VRS approach has always been widely accepted and acknowledged by researchers as a CRS would lead to contraction or expansion of the activity of any firm [17]. Portela et al. [29] cited an example to display the inherent fallacy of the model. Allahyar and Malkhalifeh [2] presented an approach to resolve the issue of RTS. Authors induced the theme of a neighbourhood analysis to observe the changes in the output and input sets. Sahoo et al. [31], however, pointed out the inability of the model to explore the CRS efficient DMUs \& also the Most Productive Scale Size (MPSS). Authors proposed an alternative non-radial model to eradicate these problems. During 2016, Inverse DEA was proposed by Amin and Muharram [3] to rectify the problems of negative data in the domain of mergers by two or more firms.

Erstwhile Super Efficiency models were incapable of dealing with negative data which could even discriminate firms which scored $100 \%$ efficiency scores. Lin and Chen [22] developed a new radial super-efficiency model which could involve both negative and positive values of input-output variables. "It successfully addresses the infeasibility issue of both the conventional radial super-efficiency DEA model and the Nerlove-Luenberger superefficiency DEA model under the assumption of variable returns to scale." On the other hand, Wei et al. [38] 
proposed a new modified slacks-based method had the properties of unit invariance and translation invariance, and it can give targets for inefficient DMUs to guide them to achieve full efficiency.

The brief of this contemporary research hovers around two points. One group (such as $[27,29]$ ) favoured the relocation of origin and permits the transformation of the data set to allow the application of regular methods. Some even stayed with the same origin and proposed models to obtain VRS efficient DMUs. However, no one even patronized the possibility of CRS. The extant tenet is clarifying the existence of Pseudo CRS which may either be commencing from the true origin or a relocated one prescribed by the model itself (truly supported by [2]). In brief, an operation of a firm can be expanded or contracted in a proportional manner may be from the origin or a relocated origin.

The entire research is aimed to motivate the search of a new origin which would not only assist in transforming the negative data into positive but also would discriminate the CRS efficient DMUs from the VRS efficient ones. A successful search would produce three major benefits in the following domains:

- Determination of a new origin which is suitable for orienting a CRS frontier.

- Computation of scale effects in case of a negative data problem.

- To verify the Most Productive Scale Size (as mentioned by [31]).

- Productivity analysis (using Malmquist Index) during a negative data problem.

- Advanced search procedures for Generalised Directional Distance Function to handle negative data without incorporating the constraint of Variable Return to Scale.

The structure of the research is as follows. Section 2 is introduced for the sake of detailing the concept of CRS and the reason for development of the RTS model prescribed by Allahyar and Malkhalifeh [2]. Section 3 delineates the way to find the slope of the CRS frontier along with the new origin while extending the RTS model. Section 4 is included for the criticism of this approach for solving a multi-input-output problem and to incorporate a new variation of Multiplier BCC model to resolve the issue. Sections 5 and 6 are added to provide a series of examples and concluding remarks in favour of the prescribed model.

\section{Problem statement}

The mathematical expressions to affirm a Constant RTS for a Production Possible Set $T$ (convex in nature) are mentioned below. Any feasible unit (member of $T$ ) which consumes a desirable input $x$ to produce a desirable output $y$, can be defined as follows: $T=\{(x, y): x$ can produce $y\}$ where $x \in R_{v}^{+}, y \in R_{m}^{+}$.

Few essential assumptions are adopted for ensuring CRS membership within the set $T$.

- If there is an activity $\left(x_{0}, y_{0}\right)$ such that, $\left(x_{0}, y_{0}\right) \in T$, then any activity $\left(k x_{0}, k y_{0}\right)$ will also be an element of $T$ (for $k>0)$.

- If there is an activity $\left(x_{0}, y_{0}\right)$ such that, $\left(x_{0}, y_{0}\right) \in T$, then any activity $\left(x_{0}, y\right)$ will also be an element of $T$ due to free disposability of outputs $\left(y \leq y_{0}\right)$.

- If there is an activity $\left(x_{0}, y_{0}\right)$ such that, $\left(x_{0}, y_{0}\right) \in T$, then any activity $\left(x, y_{0}\right)$ will also be an element of $T$ due to free disposability of inputs $\left(x \geq x_{0}\right)$.

The vector $\left(x_{0}, y_{0}\right)$ will be granted as a superior combination than $\left(x_{0}, y\right)$ or $\left(x, y_{0}\right)$. But, the first condition gets violated if the input (output) vector contains at least one negative variable. The application of CRS on the presence of negative data has been denied by many authors. Portela et al. [29] typically insinuated the reason of failure with a small example added in the Section 2. Authors expounded the inability of the radial direction for DMU 3 to predict an appropriate peer (Fig. 1 (reiterated from [29])). The crisis was due to the failure of the radial vector passing through DMU 3 to point out an ambiguous peer which was superior in terms of the positive output \& inferior in terms of the other.

The entire episode led to two major questions:

- Allahyar and Malkhalifeh [2] accepted a small change in the input or output vector to confirm the RTS of a firm. Can there be any existence of CRS efficient DMUs when the RTS is admitting the presence of CRS 


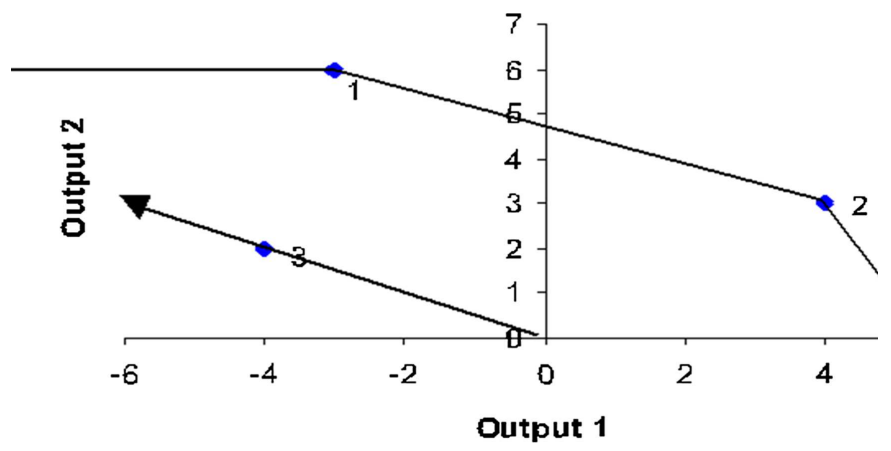

FIGURE 1. Absence of CRS frontier for negative data.

after the neighbourhood analysis? Because, this will lay the foundation of building a CRS frontier. So, is it possible to establish these facts using envelopment or a multiplier model?

- Secondly, is it possible to obtain an unambiguous origin which would favour the CRS from it?

\section{Allahyar's model \& Construction of Pseudo CRS frontier}

The tenets of Allahyar and Malkhalifeh [2] for detecting the return to scale for a negative data problem to deal with the investigation around the strongly efficient VRS based DMUs while employing the subsequent models.

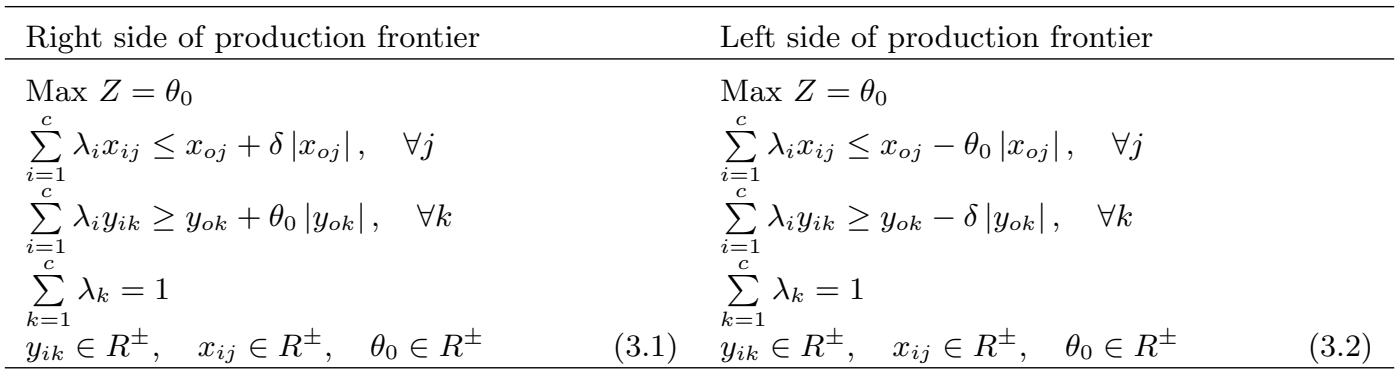

Based on the optimal scores of $\theta_{0}$ and the predefined value of $\delta$ the status of a DMU is decided. The modus operandi of the model (dealing with a negative input \& a positive output) is briefly explained in Figures $2 \mathrm{a}$ and $2 \mathrm{~b}$. A firm would be categorised as Efficient under CRS when any of the following cases occur:

- If the left side of the DMU follows IRS and subsequently adopts DRS on the Right hand side. Here, IRS implies that if the input is increased by a certain rate then the output will increase at a higher rate. On the contrary, DRS is realised if the output is reduced by a certain rate then the input will decrease at a lower rate.

- If anyone side of the DMU follows CRS (when the rate of increase or decrease will transpire equally for both input \& output).

The second condition provides a clear picture of the origin as the entire facet depicts the linear equation of CRS frontier. However, the first case does not offer any clear message about the location of the origin. It could be within any two intersecting points obtained from the extension of the lines $\mathrm{AB}$ and $\mathrm{AC}$ with input axis. In order to obtain the new origin the principle of Allahyar and Malkhalifeh [2] is adopted. A CRS efficient DMU can only be created outside the boundary spanned by VRS by increasing input and output at an equal rate. 
(a)

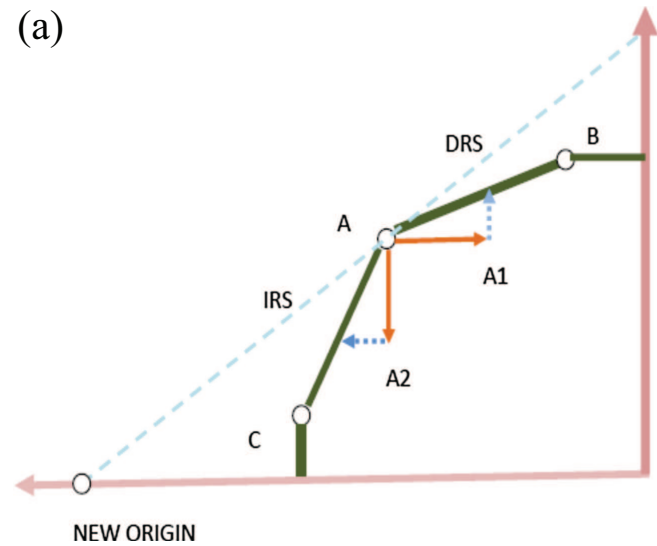

(b)

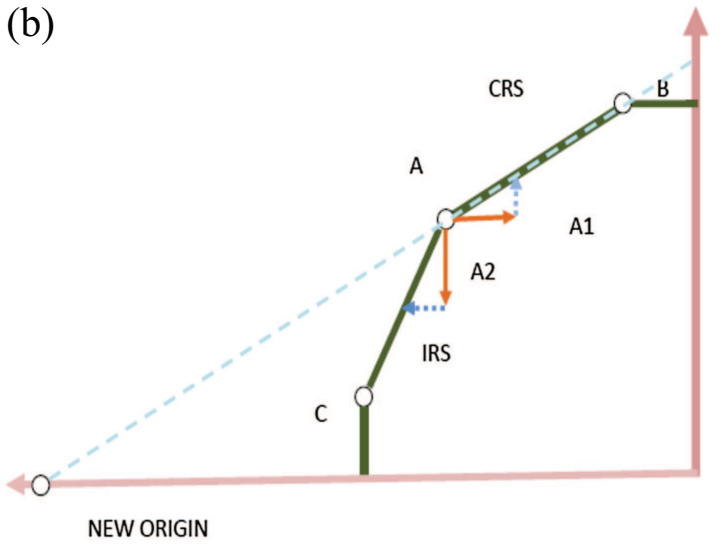

Figure 2. (a) CRS due to IRS \& DRS. (b) CRS due to IRS \& CRS.

The line joining the current DMU and the new point will have a positive slope and will certainly intersect the abscissa to create a new origin.

The traditional concept of CRS is elaborated on the basis of an equality while allowing strictly positive values for both input $(x) \&$ output $(y)$ :

$$
\frac{\mathrm{d} x}{x}=\frac{\mathrm{d} y}{y}=\omega
$$

This equation iterates the necessary \& sufficient condition of having a CRS technology in existence. Here, the rate of $\%$ change (rise or fall) of the input should be same as $\%$ change of the output. The solution of this differential equation leads to a linear equation $y=m x$ (where $m$ is the slope of the straight line). The solution itself characterises the production frontier. However, the scenario gets changed if any one of them is converted to negative. The resulting solution, $y=m|x|$ for $m, y>0$, in such a scenario would reflect a connectivity among a desirable output and an undesirable input. Hence, a production frontier (which is concave in nature) is expected to contain a point which would satisfy the condition as mentioned as

$$
\left[\frac{\mathrm{d} y}{\mathrm{~d} x}\right]_{x=x_{0}}=\left[\frac{y}{|x|}\right]_{x=x_{0}} \quad \text { for } \quad x<0 \& y>0 .
$$

The model suggested by Allahyar and Malkhalifeh [2] was aligned as per following rule to eradicate this crisis owing to a negative data. To deal with the left hand side problem, $\omega$ is held as a constant for the output set. On the other hand, it is kept fixed for the right hand side problem.

$$
\frac{\mathrm{d} x}{|x|}=\frac{\mathrm{d} y}{|y|}=\omega \quad \text { or } \quad \frac{\mathrm{d} y}{\mathrm{~d} x}=\frac{|y|}{|x|} .
$$

\subsection{Determination of slope of the Pseudo CRS frontier}

Under a single input-output problem, a VRS efficient DMU-O can have four input output combinations such as $\left(x_{i j}, y_{i k} \in R^{+}\right),\left(x_{i j}, y_{i k} \in R^{-}\right),\left(x_{i j} \in R^{-}, y_{i k} \in R^{+}\right)$and $\left(x_{i j} \in R^{+}, y_{i k} \in R^{-}\right)$. Considering the third type of the sign restriction on the model of Allahyar and Malkhalifeh [2] leads to two subsequent forms.

Two mathematical forms emerge as a mere reorientation of the terms is made on (3.1) and (3.2). These models are truly representatives of a Decreasing RTS problem.

Hence, the choice of the positive value of $\delta$ will make the transition of both problems from VRS towards a DRS. It is quite easy to comprehend the similarities among the models referred in (3.3) to (3.6). For an infinitely small 


\begin{tabular}{|c|c|}
\hline Right side of production frontier & Left side of production frontier \\
\hline $\begin{array}{l}\operatorname{Max} Z=\theta_{0} \\
\sum_{i=1}^{c} \lambda_{i} x_{i j} \leq x_{o j}+\delta\left|x_{o j}\right|, \quad j=1 \\
\sum_{i=1}^{c} \lambda_{i} y_{i k} \geq y_{o k}+\theta_{0}\left|y_{o k}\right|, \quad k=1 \\
\sum_{i=1}^{c} \lambda_{i}=1 \\
y_{i k} \in R^{ \pm}, \quad x_{i j} \in R^{ \pm}, \quad \theta_{0} \in R^{ \pm}\end{array}$ & $\begin{array}{l}\operatorname{Max} Z=\theta_{0} \\
\sum_{i=1}^{c} \lambda_{i} x_{i j} \leq x_{o j}-\theta_{0}\left|x_{o j}\right|, \quad j=1 \\
\sum_{i=1}^{c} \lambda_{i} y_{i k} \geq y_{o k}-\delta\left|y_{o k}\right|, \quad k=1 \\
\sum_{i=1}^{c} \lambda_{i}=1 \\
y_{i k} \in R^{ \pm}, \quad x_{i j} \in R^{ \pm}, \quad \theta_{0} \in R^{ \pm}\end{array}$ \\
\hline Right side of production frontier & Left side of production frontier \\
\hline $\begin{array}{l}\operatorname{Max} Z=\theta_{0} \\
\sum_{i=1}^{c} \lambda_{i}^{\prime} x_{i j} \leq x_{o j}, \quad j=1 \\
\sum_{i=1}^{c} \lambda_{i}^{\prime} y_{i k} \geq y_{o k}\left(1+\theta_{0}+\delta\right), \quad k=1 \\
\sum_{i=1}^{c} \lambda_{i}^{\prime}=1+\delta, \quad \ni \lambda_{i}^{\prime}=\left\{\begin{array}{ll}\lambda_{0}+\delta & i=0 \\
\lambda_{i} & i \neq 0\end{array}\right\}^{+} \quad x_{i j} \in R^{-}, \quad \theta_{0} \in R^{ \pm}\end{array}$ & $\begin{array}{l}\operatorname{Max} Z=\theta_{0} \\
\sum_{i=1}^{c} \lambda_{i}^{\prime} x_{i j} \leq x_{o j}\left(1+\theta_{0}+\delta\right), \quad j=1 \\
\sum_{i=1}^{c} \lambda_{i}^{\prime} y_{i k} \geq y_{o k}, \quad k=1 \\
\sum_{i=1}^{c} \lambda_{i}^{\prime}=1+\delta, \quad \ni \lambda_{i}^{\prime}=\left\{\begin{array}{ll}\lambda_{0}+\delta & i=0 \\
\lambda_{i} & i \neq 0\end{array}\right\} \\
y_{i k} \in R^{+}, \quad x_{i j} \in R^{-}, \quad \theta_{0} \in R^{ \pm}\end{array}$ \\
\hline
\end{tabular}

value of $\delta$ both would converge into radial models for measuring inefficiency scores. However, in terms of locating an optimal solution in the space, there is a remarkable difference. The former models recognise solutions within the space defined by the VRS whereas the later models yield solutions laying beyond it. The space defined by VRS is a subset of a space defined by CRS. At the limiting stage the optimal solutions of the second set of models seem to be approaching towards CRS space. This phenomenon is utilised for orienting the CRS frontier.

Let, two optimal solutions obtained from the above two models are referred as $\theta_{0 i}^{*}(\delta)$ and $\theta_{0 o}^{*}(\delta)$. Eventually, it will result a pair of peers denoted as follows:

$$
\left(x_{o}, y_{o}\left(1+\theta_{0 o}^{*}(\delta)+\delta\right)\right) \text { and }\left(x_{o}\left(1+\theta_{0 i}^{*}(\delta)+\delta\right), y_{o}\right) .
$$

These two points will certainly be useful to detect the slope of the CRS. Hence, the slope of the CRS frontier will be computed as follows:

$$
S=\frac{\left(y_{o}\left(1+\theta_{0 o}^{*}(\delta)+\delta\right)-y_{o}\right)}{\left(x_{o}-x_{o}\left(1+\theta_{0 i}^{*}(\delta)+\delta\right)\right)}=\left(\frac{y_{o}}{\left|x_{o}\right|}\right)\left(\frac{\theta_{0 o}^{*}(\delta)+\delta}{\theta_{0 i}^{*}(\delta)+\delta}\right) .
$$

However, according to Allahyar and Malkhalifeh [2] any CRS efficient DMU can only remain efficient if the equality of $\theta_{0 o}^{*}(\delta)=\theta_{0 i}^{*}(\delta)=\delta$ exists. Hence, it can be ensured that any CRS efficient DMU would possess a slope equivalent to $S=\left(\frac{y_{o}}{\left|x_{o}\right|}\right)$. In other words, once the CRS efficient point is located then utilising $S$ the intercept on $x$ axis can also be located. This new point can be conceived as a representative of the new origin for the negative input. In this case, the coordinate of this new origin will be $\left(2 x_{o}, 0\right)$. However, according to this model a CRS frontier is unable to contain two or more DMUs on it. The following theorem is referred to ensure this proposition.

Theorem 3.1. Under a single negative input $\mathscr{E}$ positive output scenario a single CRS Efficient Solution can only exist.

Proof. Let there be at least two CRS efficient DMUs (say, $t$ th and $u$ th) situated on the production frontier. As a result, the slopes obtained owing to these points will be $S_{t}=\left(\frac{y_{t}}{\left|x_{t}\right|}\right)$ and $S_{u}=\left(\frac{y_{u}}{\left|x_{u}\right|}\right)$. Moreover, these slopes will be equivalent to each other $\left(S_{t}=S_{u}\right)$.

$$
\left(\frac{y_{t}}{\left|x_{t}\right|}\right)=\left(\frac{y_{u}}{\left|x_{u}\right|}\right)
$$


Since, both units are different from each other, so, it is assumed that the input output vectors are not identical to each other. In this regard, two inequalities such as $x_{t}<x_{s}$ and $y_{t}<y_{s}$ are considered here. But, it these relationships also approve that $\left|x_{t}\right|>\left|x_{s}\right|$ and $y_{t}<y_{s}$ which consequently, affirms an inequality proposition shown as $\left(\frac{y_{t}}{\left|x_{t}\right|}<\frac{y_{s}}{\left|x_{s}\right|}\right)$. Hence, such slopes can only ensure the presence of one and only one CRS efficient DMU.

Similarly, forth condition will present a slope $S=\left(\frac{\left|y_{o}\right|}{x_{o}}\right)$ along with a new origin located at $\left(0,2 y_{o}\right)$. On the other hand, the first and second conditions give rise to slopes of $S=\left(\frac{y_{o}}{x_{o}}\right)$ and $S=\left(\frac{\left|y_{o}\right|}{\left|x_{o}\right|}\right)$ while having the origin situated at $(0,0)$.

\subsection{Derivation of the CRS frontier}

It can therefore be convincingly claimed that the same CRS efficient DMUs will be reinstate if the data is properly transformed based on the specified origins. Thus, the extended research simply aims to apply a Pseudo CRS framework by relocating the origin. In this context, a theorem is added below to approve the equivalence between the outcome of a Pseudo CRS model and the model proposed by Allahyar and Malkhalifeh [2].

Theorem 3.2. In a DEA problem with single input (negative type) and output (positive data) the DMU displaying CRS will remain as a CRS efficient DMU after the relocation of the origin in a stipulated manner.

Proof. Let the origin be shifted from $(0,0)$ to $(a, 0)$ such that the quantity $\left(x_{i j}+a\right)$ always remain as strictly positive for all values of $i$. Hence, adoption of the input oriented CRS model for any DMU O will subsequently measure its efficiency score among the other rivals.

$$
\begin{aligned}
& \text { Min }=\theta \\
& \sum_{i=1}^{c} \lambda_{i}\left(x_{i j}+a\right) \leq \theta\left(x_{o j}+a\right), \quad j=1 \\
& \sum_{i=1}^{c} \lambda_{i} y_{i k} \geq y_{o k}, \quad k=1 \\
& y_{i k} \in R^{+}, \quad x_{i j} \in R^{-} .
\end{aligned}
$$

Now, replacing $\lambda_{k}$ by $\lambda_{k}^{\prime}$ while defining $\lambda_{k}^{\prime}=\left\{\begin{array}{ll}\lambda_{i} & i \neq 0 \\ \lambda_{o}-\delta & i=0\end{array}\right\}$, the following set of constraints are obtained.

$$
\begin{aligned}
& \operatorname{Min}=\theta \\
& \sum_{i=1}^{c} \lambda_{i}^{\prime} x_{i j} \leq x_{o j}-\delta x_{o j}-x_{o j}+\theta\left(x_{o j}+a\right)-a \sum_{i=1}^{c} \lambda_{i}, \\
& \sum_{i=1}^{c} \lambda_{i}^{\prime} y_{i k} \geq y_{o k}-\delta\left|y_{o k}\right|, \quad \text { as } \quad\left|y_{o k}\right|=y_{o k} .
\end{aligned}
$$

A mere rearrangement of these terms will consequently lead to the following optimization problem:

$$
\begin{aligned}
& \operatorname{Min} W=\theta \\
& \sum_{i=1}^{c} \lambda_{i}^{\prime} x_{i j} \leq x_{o j}-\beta\left|x_{o j}\right|, \\
& \sum_{i=1}^{c} \lambda_{i}^{\prime} y_{i k} \geq y_{o k}-\delta\left|y_{o k}\right| \\
& \beta=\left[(u-1)(1+\delta-\theta)+u\left(\sum_{i=1}^{c} \lambda_{i}^{\prime}-1\right)\right] .
\end{aligned}
$$

$a=u\left|x_{o j}\right|$ such that $u>1$ (as shown in the previous section). 
The model has an alternative expression akin to the one origated by Allahyar and Malkhalifeh [2].

$$
\begin{aligned}
& \operatorname{Max} Z=\beta-u t \\
& \sum_{i=1}^{c} \lambda_{i}^{\prime} x_{i j} \leq x_{o j}-\beta\left|x_{o j}\right|, \\
& \sum_{i=1}^{c} \lambda_{i}^{\prime} y_{i k} \geq y_{o k}-\delta\left|y_{o k}\right|, \\
& \beta=(u-1)(1+\delta-\theta)+u t, \quad \text { as } \quad u>1, \\
& t=\sum_{i=1}^{c} \lambda_{i}^{\prime}-1
\end{aligned}
$$

The optimal solution of this problem will certainly squeeze the value of $t$ to zero to offer a relationship of $\theta=(1+\delta)-\frac{\beta^{*}}{(u-1)}$. If the same DMU exhibits the property of a strongly efficient member in the above mentioned CRS model, then the corresponding efficiency score will be $\theta^{*}=1$. But, at this point the condition of $u=2$ should emerge from the above section to justify the equivalence of $\delta=\beta^{*}$. It literally approves the existence of CRS on the left side of the frontier (second model shown above) (originated by [2]) $\delta=\beta^{*}$. Similar ways will also lead to the existence of CRS on the right side as well. Hence, it is concluded that a CRS efficient DMU obtained from the transformed data will certainly exhibits the CRS condition delineated by Allahyar and Malkhalifeh [2].

\subsection{Problem with the method for detecting CRS efficient DMU}

This process of identification ceases to work when a multiple input output negative data problem is assumed. The existence of a number of CRS efficient DMUs will certainly prevent the selection of the justified slope which would be utilised to explore the new origin. In this regard, a new variation of BCC multiplier model is proposed to serve the purpose. Most importantly, this framework ceases to support when a VRS efficient DMU possesses a zero value in either input or output. However, it can be rectified by replacing the zero value with a very small unit of positive value.

\section{Multiplier MODELS FOR NEGATive DATA}

This segment is keen to demonstrate a generalised multiplier model to allow any type of multi-input \& output data. Bearing in mind to the previously stated proofs and facts, five combinations such as strictly positive inputs and outputs, strictly negative inputs and outputs, strictly positive inputs and mixed outputs and mixed inputs and strictly positive outputs, are created. A mixed variable can attain positive, negative or zero values. Each of these varieties is needed to be furnished with their own specific models.

Case 1. Multiplier Model for strictly positive inputs and outputs.

The linear equation, $a x=c y$ is used to create the production frontier for a single input $(x)$ output $(y)$ problem. Pursuing the same principle the model will give rise to original Multiplier Model of DEA originated by CCR.

Case 2. Multiplier Model for strictly negative inputs and outputs.

In this case, the production frontier is defined by the linear equation, $a x+b_{1}=c y+b_{2}$, where $a, c, b_{1}, b_{2}>0$. The original Multiplier Model of DEA originated by CCR will be enough for determining efficiency scores and Pseudo CRS frontier.

Case 3. Multiplier Model for strictly positive inputs and mixed outputs. 
Conceiving the single input output scenario, the frontier will certainly change its intercept.

$$
\begin{aligned}
& \operatorname{Max} Z=\sum_{i=1}^{n_{o}} c_{i} y_{i o}+b \\
& \overline{\sum_{i=1}^{n_{o}} c_{i} y_{i j}+b \leq \sum_{i=1}^{n_{i}} a_{i} x_{i j}} \\
& \sum_{i=1}^{n_{i}} a_{i} x_{i o}=1 \\
& \sum_{i=1}^{n_{o}} c_{i} y_{i j}+b \geq 0 \\
& y_{i j} \in R^{-}, \quad x_{i k} \in R^{+} \\
& a_{i}, c_{i}, b \geq 0, \quad i=1,2, \ldots, n_{D}, \quad k=1,2, \ldots, n_{o}, \quad j=1,2, \ldots, n_{i} .
\end{aligned}
$$

The frontier will pursue a linear equation demonstrated as $a x=c y+b$, where $a, c>0$ and $b$ to be an unrestricted parameter. Hence, the final model in this case is given in the model (4.1).

Case 4. Multiplier Model for mixed inputs and strictly positive outputs.

In this scenario, model (4.2) mentioned above will be very effective.

$$
\begin{aligned}
& \operatorname{Max} Z=\sum_{i=1}^{n_{o}} c_{i} y_{i o} \\
& \overline{\sum_{i=1}^{n_{o}} c_{i} y_{i j} \leq \sum_{i=1}^{n_{i}} a_{i} x_{i j}+b} \\
& \sum_{i=1}^{n_{i}} a_{i} x_{i o}+b=1 \text { such that } b \geq 1+\Delta \& \Delta \approx 0 \\
& \sum_{i=1}^{n_{i}} a_{i} x_{i j}+b \geq 0 \\
& y_{i j} \in R^{+}, \quad x_{i k} \in R^{-} \\
& a_{i}, c_{i}, b \geq 0, \quad i=1,2, \ldots, n_{D}, \quad k=1,2, \ldots, n_{o}, \quad j=1,2, \ldots, n_{i} .
\end{aligned}
$$

Case 5. Multiplier Model for mixed inputs and outputs.

In case of a mixed multi-input output problem, a CRS efficient DMU may possess any type of input output vector. In this regard, two nonnegative variables say, $b_{1}$ and $b_{2}$ are addressed in the model. $b_{1}$ may be equivalent to $b_{2}$ or may not be. These variables will be the determinants for locating the new origin for the given problem. 
However, it has to be kept in mind that for the sake of declaring a DMU as CRS efficient one has to utilise the method proposed by Allahyar and Malkhalifeh [2]. The search of the origin will be followed once the detection is over.

$$
\begin{aligned}
& \overline{\operatorname{Max} Z=\sum_{i=1}^{n_{o}} c_{i} y_{i o}+b_{2}} \\
& \overline{\sum_{i=1}^{n_{o}} c_{i} y_{i j}+b_{2} \leq \sum_{i=1}^{n_{i}} a_{i} x_{i j}+b_{1},} \\
& \sum_{i=1}^{n_{o}} c_{i} y_{i j}+b_{2} \geq 0 \\
& \sum_{i=1}^{n_{i}} a_{i} x_{i j}+b_{1} \geq 0 \\
& \sum_{i=1}^{n_{i}} a_{i} x_{i o}+b_{1}=1 \text { such that } b_{1} \geq 1+\Delta, \quad \text { for } \Delta \approx 0 \\
& y_{i j} \in R^{ \pm}, \quad x_{i k} \in R^{ \pm}, \\
& a_{i}, c_{i}, b_{1}, b_{2} \geq 0, \quad i=1,2, \ldots, n_{D}, \quad k=1,2, \ldots, n_{o}, \quad j=1,2, \ldots, n_{i} .
\end{aligned}
$$

None of these models are susceptible to the presence of zero values in any observed input or output variable.

\subsection{Selection of the new origin}

The selection process is to choose one from a large pool (as there can be large number of points which would be considered as legitimate points). The key objective of including such a process is to ensure that the slopes of the lines joining the new origin and the CRS efficient DMUs should not be same as a VRS efficient DMU. The above mentioned variation of a regular BCC based multiplier model is aimed to select one of them with a few constraints of non-negativity for handling negative data.

- If single CRS efficient DMU is obtained from a negative data problem then the intercept on the input \& output axes are determined from the parametric values of $a_{i}, c_{i}$ and $b$ derived from the model. The point of intercept on the input axis will be located at $\left(-\emptyset_{k}, 0\right)$ when $\emptyset_{k}>0$. The value of $\emptyset_{k}$ can be determined by the ratio of the dual values $\frac{b}{a_{k}}$.

- For a large number of CRS efficient DMUs, the equations obtained from the modified BCC model are employed to determine the new origin. The input side of the linear equation due to each CRS efficient DMU is set as zero. If in case the number of unknowns are more than the number of linear equations then an Linear programming model with artificial variables is needed to solved. The solution from this model will lead to the location of the new origin for the input side. Similar steps are prescribed for the output side as well.

\subsection{Limitation of the model}

Quite a few disadvantages can be listed in this regard. The model provides a three stepped approach. Firstly, it has to identify the list of VRS efficient DMUs followed by the screening of CRS efficient DMUs out of this list. The third step is required for orienting CRS frontier. However, there can be a major crisis while screening 
TABle 1. Data table.

\begin{tabular}{lll}
\hline \hline & Input & Output \\
\hline A & -10 & 20 \\
B & -15 & 39 \\
C & -27 & 27 \\
D & -20 & 20 \\
$\mathrm{E}$ & -18 & 28 \\
$\mathrm{~F}$ & -17 & 23 \\
\hline
\end{tabular}

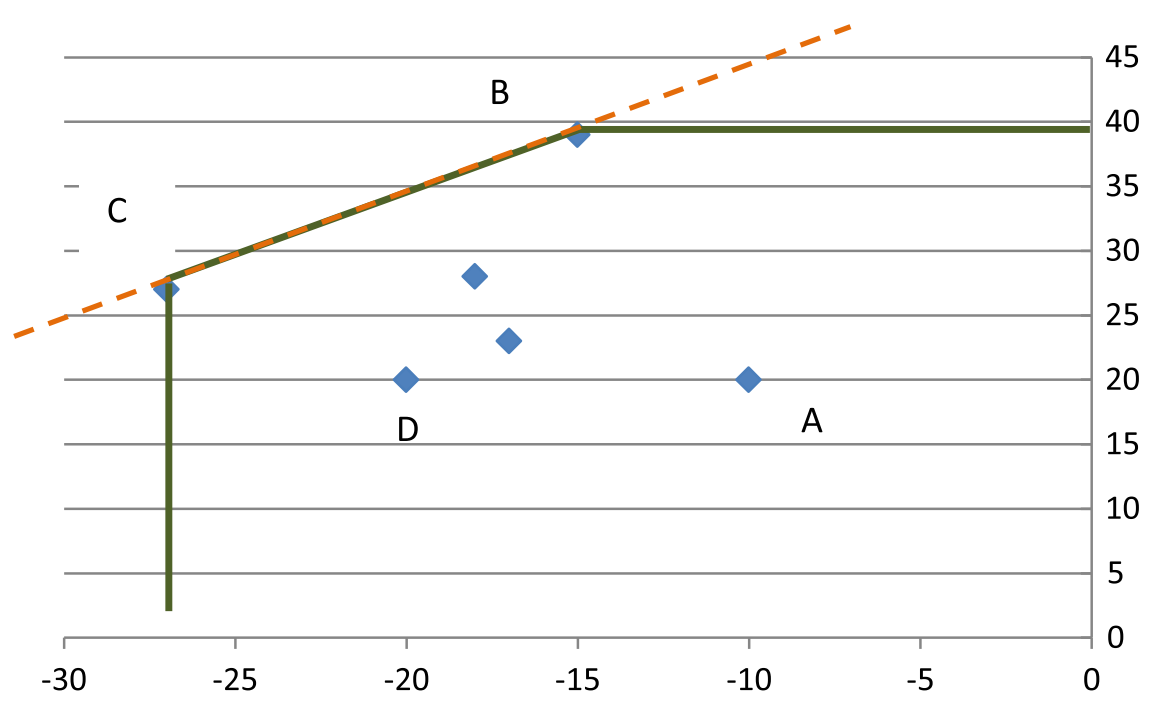

Figure 3. Example.

CRS items from the VRS efficient list in presence of zero values. It is suggested that the principles of Sahoo et al. [31] can alternatively be used as an alternative. Secondly, it is observed that the last step requires a careful attention as only CRS efficient DMUs are expected to be fed in this case. Moreover, the choice of $\Delta$ matters most as there can be non-zero parametric values as lower than that which has to disregard.

\section{EXAMPLE}

\subsection{Case with single negative input \& single positive output}

To realise the effectiveness of the model an example of single negative input data along with a positive output is brought under consideration (Tab. 1). The graphical view of this example (mentioned in Fig. 3) acknowledges the presence of two VRS efficient firms $(\mathrm{B}(-15,39)$ and $\mathrm{C}(-27,27))$.

Application of the model prescribed by Allahyar and Malkhalifeh [2] confirms the presence of CRS for the firm C only (Tab. 2). Objective scores of $\mathrm{C}$ indicate the presence of IRS and CRS on its left and right side. For example, the optimal solution on the right side of $\mathrm{C}$ is 0.001 (on the AI row in Tab. 2) is same as the premeditated value 0.001 (on the CI row in Tab. 2). On the contrary, B displays the existence of DRS on its both sides (as initial \% reduction of output set of 0.1 would lead no change found for the input set (left side condition)). 
TABLE 2. Detection of RTS for the VRS efficient DMUs.

\begin{tabular}{|c|c|c|c|c|c|c|c|c|}
\hline & DMU C & LHS & DMU B & LHS & DMU C & RHS & DMU B & RHS \\
\hline Variable & Value & $\begin{array}{l}\text { Reduced } \\
\text { cost }\end{array}$ & Value & $\begin{array}{l}\text { Reduced } \\
\text { cost }\end{array}$ & Value & $\begin{array}{l}\text { Reduced } \\
\text { cost }\end{array}$ & Value & $\begin{array}{l}\text { Reduced } \\
\text { cost }\end{array}$ \\
\hline $\mathrm{AI}$ & 0.000 & 0.000 & 0.003 & 0.000 & 0.001 & 0.000 & 0.000 & 0.000 \\
\hline$L_{1}$ & 0.000 & 0.630 & 0.000 & 1.600 & 0.000 & 0.889 & 0.000 & 0.487 \\
\hline$L_{2}$ & 0.000 & 0.444 & 0.997 & 0.000 & 0.002 & 0.000 & 1.000 & 0.000 \\
\hline$L_{3}$ & 1.000 & 0.000 & 0.003 & 0.000 & 0.998 & 0.000 & 0.000 & 0.308 \\
\hline$L_{4}$ & 0.000 & 0.259 & 0.000 & 0.933 & 0.000 & 0.519 & 0.000 & 0.487 \\
\hline$L_{5}$ & 0.000 & 0.333 & 0.000 & 0.533 & 0.000 & 0.296 & 0.000 & 0.282 \\
\hline$L_{6}$ & 0.000 & 0.370 & 0.000 & 0.933 & 0.000 & 0.519 & 0.000 & 0.410 \\
\hline CI & 0.001 & 0.000 & 0.001 & 0.000 & 0.001 & 0.000 & 0.001 & 0.000 \\
\hline Row & $\begin{array}{c}\text { Slack or } \\
\text { Surplus }\end{array}$ & $\begin{array}{l}\text { Dual } \\
\text { price }\end{array}$ & $\begin{array}{l}\text { Slack or } \\
\text { Surplus }\end{array}$ & $\begin{array}{l}\text { Dual } \\
\text { price }\end{array}$ & $\begin{array}{l}\text { Slack or } \\
\text { Surplus }\end{array}$ & $\begin{array}{l}\text { Dual } \\
\text { price }\end{array}$ & $\begin{array}{l}\text { Slack or } \\
\text { Surplus }\end{array}$ & $\begin{array}{l}\text { Dual } \\
\text { price }\end{array}$ \\
\hline 1.000 & 0.000 & 0.037 & 0.000 & 0.067 & 0.000 & 0.037 & 0.015 & 0.000 \\
\hline 2.000 & 0.027 & 0.000 & 0.000 & -0.067 & 0.000 & -0.037 & 0.000 & -0.026 \\
\hline 3.000 & 0.000 & 1.000 & 0.000 & 3.600 & 0.000 & 2.000 & 0.000 & 1.000 \\
\hline 4.000 & 0.000 & 0.000 & 0.000 & 2.600 & 0.000 & 1.000 & 0.000 & 0.000 \\
\hline & IRS & & DRS & & CRS & & DRS & \\
\hline
\end{tabular}

TABLE 3. CRS efficiency score of DMUs.

\begin{tabular}{llll}
\hline \hline DMU & Input & Output & Efficiency \\
\hline A & 44 & 20 & 0.455 \\
$\mathrm{~B}$ & 39 & 39 & 1.000 \\
$\mathrm{C}$ & 27 & 27 & 1.000 \\
$\mathrm{D}$ & 34 & 20 & 0.588 \\
$\mathrm{E}$ & 36 & 28 & 0.778 \\
$\mathrm{~F}$ & 37 & 23 & 0.622 \\
\hline
\end{tabular}

Pursuing this conclusion the slope as well as the point of interception on $x$ axis are found to be $S=1$ and $(-54,0)$ respectively. Relocating the origin from $(0,0)$ to $(-54,0)$ results a new dataset cited in Table 3 . A mere ratio test is conducted on this data to compute the efficiency scores of each of these DMUs. It can be observed that though the formal approach can reveal only one CRS efficient DMU but present numeric values of B have also allowed it to become another member of the same group.

On the contrary, a strange phenomenon is observed if the outcome of the prescribed multiplier model on the VRS efficient DMUs (B and C) is scrutinised. C is the only one member which is able score all positive coefficients for the linear equation $L_{1} x+L_{3}=L_{2} y$ used for defining the Pseudo CRS production frontier. Here, $(x, y)$ is the input output vector of the contesting members. Most importantly, the intercept obtained from the optimal solution of $\mathrm{C}$ given in Table 4 is $\frac{L_{3}}{L_{2}}=54$ (which is same as the previous value obtained from the envelopment model). Hence, the multiplier model is found quite reliable to identify the CRS frontier and CRS efficient DMUs. The success of this multiplier model is solely attributed to the value of $L_{3}$ which remains above one in both cases. Hence, in a nutshell, the problem involving mixed input data should have a constraint $L_{3} \geq 1+\Delta$ where $\Delta \approx 0$.

The proposed multiplier model in this case will raise a question whether the entire theory can be pertinent to a mixed type of Multi-Input \& Output problem or not. 
TABle 4. Outputs of Pseudo CRS multiplier model.

\begin{tabular}{|c|c|c|c|c|}
\hline \multirow[b]{2}{*}{ Variable } & \multicolumn{2}{|c|}{ DMU B } & \multicolumn{2}{|c|}{ DMU C } \\
\hline & Value & $\begin{array}{r}\text { Reduced } \\
\text { cost } \\
\end{array}$ & Value & $\begin{array}{r}\text { Reduced } \\
\text { cost } \\
\end{array}$ \\
\hline$Z$ & 1.000 & 0.000 & 1.000 & 0.000 \\
\hline$L_{2}$ & 0.026 & 0.000 & 0.037 & 0.000 \\
\hline$L_{3}$ & 1.015 & 0.000 & 2.000 & 0.000 \\
\hline$L_{1}$ & 0.001 & 0.000 & 0.037 & 0.000 \\
\hline Row & $\begin{array}{l}\text { Slack or } \\
\text { Surplus }\end{array}$ & $\begin{array}{l}\text { Dual } \\
\text { price }\end{array}$ & $\begin{array}{l}\text { Slack or } \\
\text { Surplus }\end{array}$ & $\begin{array}{l}\text { Dual } \\
\text { price }\end{array}$ \\
\hline 1.000 & 0.000 & 1.000 & 0.000 & 1.000 \\
\hline 2.000 & 0.492 & 0.000 & 0.889 & 0.000 \\
\hline 3.000 & 0.000 & -1.000 & 0.000 & 0.000 \\
\hline 4.000 & 0.296 & 0.000 & 0.000 & -1.000 \\
\hline 5.000 & 0.482 & 0.000 & 0.519 & 0.000 \\
\hline 6.000 & 0.279 & 0.000 & 0.296 & 0.000 \\
\hline 7.000 & 0.408 & 0.000 & 0.519 & 0.000 \\
\hline 8.000 & 0.000 & 1.000 & 0.000 & 1.000 \\
\hline 9.000 & 0.000 & 0.000 & 0.036 & 0.000 \\
\hline 10.000 & 0.025 & 0.000 & 0.036 & 0.000 \\
\hline
\end{tabular}

TABle 5. Data Table 2.

\begin{tabular}{llrr}
\hline \hline & Input 1 & Input 2 & Output \\
\hline $\mathrm{A}$ & -10 & 4 & 21 \\
$\mathrm{~B}$ & -15 & 10 & -17 \\
$\mathrm{C}$ & -27 & -5 & -6 \\
$\mathrm{D}$ & -20 & 12 & 18 \\
$\mathrm{R}$ & -18 & 30 & 35 \\
$\mathrm{~F}$ & -17 & -2 & -18 \\
$\mathrm{G}$ & -12 & -1 & 26 \\
$\mathrm{H}$ & -21 & 4 & 28 \\
$\mathrm{I}$ & -19 & 6 & -11 \\
$\mathrm{~J}$ & -16 & -5 & 10 \\
\hline
\end{tabular}

\subsection{Case with mixed type of multi-input \& output problem}

The proposed model (4.3) is required to be applied on the VRS efficient DMUs obtained from the SBM. C, E, G, H \& J are found to be efficient among the 10 DMUs (Tab. 5) depicted in the Table 6.

The consequence of the application of (3C) (shown in Tab. 7) portrays two varieties of linear equations (Tab. 8). These two emerged from $\mathrm{E} \& \mathrm{H}$ whereas the remaining DMUs did have zero values as the optimal parametric values. In other words, these parametric values do provide required information about the Pseudo CRS frontier.

Table 8 primarily reflects the information about the new origin. Such as in both cases $L_{5}$ has a same value of 18 . Hence, $y$ has to initiate from -18 . Similarly, the coordinates belong to two inputs are obtained after solving 
TABLE 6. Outputs of SBM.

\begin{tabular}{|c|c|c|c|c|c|c|c|c|c|c|}
\hline \multirow[b]{2}{*}{ Variable } & \multicolumn{2}{|c|}{$\mathrm{A}$} & \multicolumn{2}{|c|}{ B } & \multicolumn{2}{|c|}{$\mathrm{C}$} & \multicolumn{2}{|c|}{$\mathrm{D}$} & \multicolumn{2}{|c|}{$\mathrm{E}$} \\
\hline & Value & $\begin{array}{l}\text { Reduced } \\
\text { cost }\end{array}$ & Value & $\begin{array}{l}\text { Reduced } \\
\text { cost }\end{array}$ & Value & $\begin{array}{l}\text { Reduced } \\
\text { cost }\end{array}$ & Value & $\begin{array}{l}\text { Reduced } \\
\text { cost }\end{array}$ & Value & $\begin{array}{l}\text { Reduced } \\
\text { cost }\end{array}$ \\
\hline$Z$ & 18.000 & 0.000 & 57.000 & 0.000 & 0.000 & 0.000 & 19.000 & 0.000 & 0.000 & 0.000 \\
\hline$S_{1}$ & 11.000 & 0.000 & 6.000 & 0.000 & 0.000 & 0.455 & 1.000 & 0.000 & 0.000 & 0.000 \\
\hline$S_{2}$ & 0.000 & 1.200 & 6.000 & 0.000 & 0.000 & 1.808 & 8.000 & 0.000 & 0.000 & 0.000 \\
\hline$S_{3}$ & 7.000 & 0.000 & 45.000 & 0.000 & 0.000 & 0.000 & 10.000 & 0.000 & 0.000 & 3.143 \\
\hline$L_{1}$ & 0.000 & 18.000 & 0.000 & 18.000 & 0.000 & 23.000 & 0.000 & 18.000 & 0.000 & 40.000 \\
\hline$L_{2}$ & 0.000 & 64.200 & 0.000 & 57.000 & 0.000 & 70.576 & 0.000 & 57.000 & 0.000 & 198.429 \\
\hline$L_{3}$ & 0.000 & 8.200 & 0.000 & 19.000 & 1.000 & 0.000 & 0.000 & 19.000 & 0.000 & 125.857 \\
\hline$L_{4}$ & 0.000 & 28.600 & 0.000 & 19.000 & 0.000 & 33.919 & 0.000 & 19.000 & 0.000 & 50.429 \\
\hline$L_{5}$ & 0.000 & 53.200 & 0.000 & 22.000 & 0.000 & 70.374 & 0.000 & 22.000 & 1.000 & 0.000 \\
\hline$L_{6}$ & 0.000 & 36.800 & 0.000 & 44.000 & 0.000 & 34.970 & 0.000 & 44.000 & 0.000 & 188.571 \\
\hline$L_{7}$ & 0.000 & 0.000 & 0.000 & 6.000 & 0.000 & 1.051 & 0.000 & 6.000 & 0.000 & 12.286 \\
\hline$L_{8}$ & 1.000 & 0.000 & 1.000 & 0.000 & 0.000 & 0.000 & 1.000 & 0.000 & 0.000 & 0.000 \\
\hline$L_{9}$ & 0.000 & 45.400 & 0.000 & 43.000 & 0.000 & 47.525 & 0.000 & 43.000 & 0.000 & 165.571 \\
\hline$L_{10}$ & 0.000 & 3.200 & 0.000 & 14.000 & 0.000 & 0.000 & 0.000 & 14.000 & 0.000 & 70.571 \\
\hline Row & $\begin{array}{l}\text { Slack or } \\
\text { Surplus }\end{array}$ & $\begin{array}{l}\text { Dual } \\
\text { price }\end{array}$ & $\begin{array}{l}\text { Slack or } \\
\text { Surplus }\end{array}$ & $\begin{array}{l}\text { Dual } \\
\text { price }\end{array}$ & $\begin{array}{l}\text { Slack or } \\
\text { Surplus }\end{array}$ & $\begin{array}{l}\text { Dual } \\
\text { price }\end{array}$ & $\begin{array}{l}\text { Slack or } \\
\text { Surplus }\end{array}$ & $\begin{array}{l}\text { Dual } \\
\text { price }\end{array}$ & $\begin{array}{l}\text { Slack or } \\
\text { Surplus }\end{array}$ & $\begin{array}{l}\text { Dual } \\
\text { price }\end{array}$ \\
\hline 1.000 & 0.000 & 1.000 & 0.000 & 1.000 & 0.000 & 1.000 & 0.000 & 1.000 & 0.000 & 1.000 \\
\hline 2.000 & 0.000 & 1.000 & 0.000 & 1.000 & 0.000 & 1.455 & 0.000 & 1.000 & 0.000 & 1.000 \\
\hline 3.000 & 0.000 & 2.200 & 0.000 & 1.000 & 0.000 & 2.808 & 0.000 & 1.000 & 0.000 & 1.000 \\
\hline 4.000 & 0.000 & -1.000 & 0.000 & -1.000 & 0.000 & -1.000 & 0.000 & -1.000 & 0.000 & -4.143 \\
\hline 5.000 & 0.000 & 40.200 & 0.000 & 45.000 & 0.000 & 47.313 & 0.000 & 45.000 & 0.000 & 133.000 \\
\hline \multirow[b]{2}{*}{ Variable } & \multicolumn{2}{|r|}{$\mathrm{F}$} & \multicolumn{2}{|c|}{$\mathrm{G}$} & \multicolumn{2}{|c|}{$\mathrm{H}$} & \multicolumn{2}{|c|}{ I } & \multicolumn{2}{|r|}{$\mathrm{J}$} \\
\hline & Value & $\begin{array}{l}\text { Reduced } \\
\text { cost }\end{array}$ & Value & $\begin{array}{l}\text { Reduced } \\
\text { cost }\end{array}$ & Value & $\begin{array}{l}\text { Reduced } \\
\text { cost }\end{array}$ & Value & $\begin{array}{l}\text { Reduced } \\
\text { cost }\end{array}$ & Value & $\begin{array}{l}\text { Reduced } \\
\text { cost }\end{array}$ \\
\hline$Z$ & 34.857 & 0.000 & 0.000 & 0.000 & 0.000 & 0.000 & 43.000 & 0.000 & 0.000 & 0.000 \\
\hline$S_{1}$ & 0.000 & 0.286 & 0.000 & 0.286 & 0.000 & 0.455 & 2.000 & 0.000 & 0.000 & 0.455 \\
\hline$S_{2}$ & 0.000 & 1.714 & 0.000 & 1.714 & 0.000 & 1.808 & 2.000 & 0.000 & 0.000 & 1.808 \\
\hline$S_{3}$ & 34.857 & 0.000 & 0.000 & 0.000 & 0.000 & 0.000 & 39.000 & 0.000 & 0.000 & 0.000 \\
\hline$L_{1}$ & 0.000 & 21.143 & 0.000 & 21.143 & 0.000 & 23.000 & 0.000 & 18.000 & 0.000 & 23.000 \\
\hline$L_{2}$ & 0.000 & 69.000 & 0.000 & 69.000 & 0.000 & 70.576 & 0.000 & 57.000 & 0.000 & 70.576 \\
\hline$L_{3}$ & 0.000 & 1.857 & 0.000 & 1.857 & 0.000 & 0.000 & 0.000 & 19.000 & 0.000 & 0.000 \\
\hline$L_{4}$ & 0.000 & 33.000 & 0.000 & 33.000 & 0.000 & 33.919 & 0.000 & 19.000 & 0.000 & 33.919 \\
\hline$L_{5}$ & 0.000 & 67.429 & 0.000 & 67.429 & 0.000 & 70.374 & 0.000 & 22.000 & 0.000 & 70.374 \\
\hline$L_{6}$ & 0.000 & 34.857 & 0.000 & 34.857 & 0.000 & 34.970 & 0.000 & 44.000 & 0.000 & 34.970 \\
\hline$L_{7}$ & 0.107 & 0.000 & 1.000 & 0.000 & 0.000 & 1.051 & 0.000 & 6.000 & 0.000 & 1.051 \\
\hline$L_{8}$ & 0.286 & 0.000 & 0.000 & 0.000 & 1.000 & 0.000 & 1.000 & 0.000 & 0.000 & 0.000 \\
\hline$L_{9}$ & 0.000 & 47.000 & 0.000 & 47.000 & 0.000 & 47.525 & 0.000 & 43.000 & 0.000 & 47.525 \\
\hline$L_{10}$ & 0.607 & 0.000 & 0.000 & 0.000 & 0.000 & 0.000 & 0.000 & 14.000 & 1.000 & 0.000 \\
\hline Row & $\begin{array}{l}\text { Slack or } \\
\text { Surplus }\end{array}$ & $\begin{array}{l}\text { Dual } \\
\text { price }\end{array}$ & $\begin{array}{l}\text { Slack or } \\
\text { Surplus }\end{array}$ & $\begin{array}{l}\text { Dual } \\
\text { price }\end{array}$ & $\begin{array}{l}\text { Slack or } \\
\text { Surplus }\end{array}$ & $\begin{array}{l}\text { Dual } \\
\text { price }\end{array}$ & $\begin{array}{l}\text { Slack or } \\
\text { Surplus }\end{array}$ & $\begin{array}{l}\text { Dual } \\
\text { price }\end{array}$ & $\begin{array}{l}\text { Slack or } \\
\text { Surplus }\end{array}$ & $\begin{array}{l}\text { Dual } \\
\text { price }\end{array}$ \\
\hline 1.000 & 0.000 & 1.000 & 0.000 & 1.000 & 0.000 & 1.000 & 0.000 & 1.000 & 0.000 & 1.000 \\
\hline 2.000 & 0.000 & 1.286 & 0.000 & 1.286 & 0.000 & 1.455 & 0.000 & 1.000 & 0.000 & 1.455 \\
\hline 3.000 & 0.000 & 2.714 & 0.000 & 2.714 & 0.000 & 2.808 & 0.000 & 1.000 & 0.000 & 2.808 \\
\hline 4.000 & 0.000 & -1.000 & 0.000 & -1.000 & 0.000 & -1.000 & 0.000 & -1.000 & 0.000 & -1.000 \\
\hline 5.000 & 0.000 & 44.143 & 0.000 & 44.143 & 0.000 & 47.313 & 0.000 & 45.000 & 0.000 & 47.313 \\
\hline
\end{tabular}


TABle 7. Optimal table.

\begin{tabular}{|c|c|c|c|c|c|c|c|c|c|c|}
\hline \multirow[b]{2}{*}{ Variable } & \multicolumn{2}{|c|}{$\mathrm{C}$} & \multicolumn{2}{|c|}{$\mathrm{E}$} & \multicolumn{2}{|c|}{$\mathrm{G}$} & \multicolumn{2}{|c|}{$\mathrm{H}$} & \multicolumn{2}{|c|}{$\mathrm{J}$} \\
\hline & Value & $\begin{array}{l}\text { Reduced } \\
\text { cost }\end{array}$ & Value & $\begin{array}{l}\text { Reduced } \\
\text { cost }\end{array}$ & Value & $\begin{array}{l}\text { Reduced } \\
\text { cost }\end{array}$ & Value & $\begin{array}{l}\text { Reduced } \\
\text { cost }\end{array}$ & Value & $\begin{array}{l}\text { Reduced } \\
\text { cost }\end{array}$ \\
\hline$Z$ & 1.000 & 0.000 & 1.000 & 0.000 & 1.000 & 0.000 & 1.000 & 0.000 & 1.000 & 0.000 \\
\hline$L_{3}$ & 0.000 & 0.000 & 0.019 & 0.000 & 0.023 & 0.000 & 0.022 & 0.000 & 0.000 & 0.000 \\
\hline$L_{5}$ & 1.000 & 0.000 & 0.340 & 0.000 & 0.409 & 0.000 & 0.391 & 0.000 & 1.000 & 0.000 \\
\hline$L_{1}$ & 0.000 & 0.000 & 0.007 & 0.000 & 0.000 & 0.000 & 0.001 & 0.000 & 0.000 & 0.000 \\
\hline$L_{2}$ & 0.000 & 0.000 & 0.004 & 0.000 & 0.009 & 0.000 & 0.006 & 0.000 & 0.000 & 0.000 \\
\hline$L_{4}$ & 1.001 & 0.000 & 1.001 & 0.000 & 1.009 & 0.000 & 1.001 & 0.000 & 1.001 & 0.000 \\
\hline Row & $\begin{array}{c}\text { Slack or } \\
\text { Surplus }\end{array}$ & $\begin{array}{l}\text { Dual } \\
\text { price }\end{array}$ & $\begin{array}{c}\text { Slack or } \\
\text { Surplus }\end{array}$ & $\begin{array}{l}\text { Dual } \\
\text { price }\end{array}$ & $\begin{array}{c}\text { Slack or } \\
\text { Surplus }\end{array}$ & $\begin{array}{l}\text { Dual } \\
\text { price }\end{array}$ & $\begin{array}{c}\text { Slack or } \\
\text { Surplus }\end{array}$ & $\begin{array}{l}\text { Dual } \\
\text { price }\end{array}$ & $\begin{array}{c}\text { Slack or } \\
\text { Surplus }\end{array}$ & $\begin{array}{l}\text { Dual } \\
\text { price }\end{array}$ \\
\hline 1.000 & 1.001 & 0.000 & 0.736 & 0.000 & 0.886 & 0.000 & 0.848 & 0.000 & 1.000 & 0.000 \\
\hline 2.000 & 1.000 & 0.000 & 0.019 & 0.000 & 0.023 & 0.000 & 0.022 & 0.000 & 0.999 & 0.000 \\
\hline 3.000 & 1.000 & 0.000 & 0.226 & 0.000 & 0.273 & 0.000 & 0.261 & 0.000 & 1.000 & 0.000 \\
\hline 4.000 & 1.000 & 0.000 & 0.679 & 0.000 & 0.818 & 0.000 & 0.783 & 0.000 & 1.000 & 0.000 \\
\hline 5.000 & 1.001 & 0.000 & 1.000 & 0.000 & 1.205 & 0.000 & 1.152 & 0.000 & 1.001 & 0.000 \\
\hline 6.000 & 1.000 & 0.000 & 0.000 & 0.000 & 0.000 & 0.000 & 0.000 & 0.000 & 0.999 & 0.000 \\
\hline 7.000 & 1.001 & 0.000 & 0.830 & 0.000 & 1.000 & 0.000 & 0.957 & 0.000 & 1.000 & 0.000 \\
\hline 8.000 & 1.001 & 0.000 & 0.868 & 0.000 & 1.045 & 0.000 & 1.000 & 0.000 & 1.001 & 0.000 \\
\hline 9.000 & 1.000 & 0.000 & 0.132 & 0.000 & 0.159 & 0.000 & 0.152 & 0.000 & 0.999 & 0.000 \\
\hline 10.000 & 1.000 & 0.000 & 0.528 & 0.000 & 0.636 & 0.000 & 0.609 & 0.000 & 1.000 & 0.000 \\
\hline 11.000 & 0.000 & 1.000 & 0.000 & 1.000 & 0.000 & 1.000 & 0.000 & 1.000 & 0.000 & 1.000 \\
\hline 12.000 & 0.000 & 0.000 & 0.211 & 0.000 & 0.159 & 0.000 & 0.165 & 0.000 & 0.001 & 0.000 \\
\hline 13.000 & 0.001 & 0.000 & 0.917 & 0.000 & 1.077 & 0.000 & 1.019 & 0.000 & 0.002 & 0.000 \\
\hline 14.000 & 0.000 & -1.000 & 0.560 & 0.000 & 0.691 & 0.000 & 0.681 & 0.000 & 0.000 & 0.000 \\
\hline 15.000 & 0.001 & 0.000 & 0.230 & 0.000 & 0.300 & 0.000 & 0.264 & 0.000 & 0.001 & 0.000 \\
\hline 16.000 & 0.001 & 0.000 & 0.000 & -1.000 & 0.077 & 0.000 & 0.000 & 0.000 & 0.002 & 0.000 \\
\hline 17.000 & 0.001 & 0.000 & 0.871 & 0.000 & 0.991 & 0.000 & 0.970 & 0.000 & 0.001 & 0.000 \\
\hline 18.000 & 0.000 & 0.000 & 0.081 & 0.000 & 0.000 & -1.000 & 0.025 & 0.000 & 0.000 & 0.000 \\
\hline 19.000 & 0.000 & 0.000 & 0.000 & 0.000 & 0.000 & 0.000 & 0.000 & -1.000 & 0.000 & 0.000 \\
\hline 20.000 & 0.001 & 0.000 & 0.759 & 0.000 & 0.905 & 0.000 & 0.862 & 0.000 & 0.001 & 0.000 \\
\hline 21.000 & 0.000 & 0.000 & 0.337 & 0.000 & 0.327 & 0.000 & 0.345 & 0.000 & 0.000 & -1.000 \\
\hline 22.000 & 0.000 & 0.000 & 0.000 & 0.000 & 0.008 & 0.000 & 0.000 & 0.000 & 0.000 & 0.000 \\
\hline 23.000 & 0.999 & 0.000 & 0.339 & 0.000 & 0.408 & 0.000 & 0.390 & 0.000 & 0.999 & 0.000 \\
\hline
\end{tabular}

TABLE 8. Coefficients of the model parameters.

\begin{tabular}{llllll}
\hline \hline & $L_{3}$ & $L_{5}$ & $L_{1}$ & $L_{2}$ & $L_{4}$ \\
\hline $\mathrm{E}$ & 1.00000 & 18.000 & 0.3765 & 0.2258 & 53.003 \\
\hline $\mathrm{H}$ & 1.00000 & 18.000 & 0.0503 & 0.2634 & 46.046 \\
\hline
\end{tabular}

two equations shown below:

$$
\begin{aligned}
& 0.3765 x_{1}+0.2258 x_{2}+53.003=0 \\
& 0.0503 x_{1}+0.2634 x_{2}+46.046=0 .
\end{aligned}
$$

Solution of these two equations is equivalent to $x_{1}=40.714$ and $x_{2}=166.857$. Hence, the new origin will be $(-40.714,-166.857,-18)$. The data mentioned in Table 2 is needed to be transformed to create a new positive 
TABle 9. Transformed data.

\begin{tabular}{lllll}
\hline \hline & Input 1 & Input 2 & Output & Slope \\
\hline A & 30.71428 & 170.8571 & 39 & \\
B & 25.71428 & 176.8571 & 1 & \\
C & 13.71428 & 161.8571 & 12 & 0.073875 \\
D & 20.71428 & 178.8571 & 36 & \\
E & 22.71428 & 196.8571 & 53 & 0.267459 \\
F & 23.71428 & 164.8571 & 0 & \\
G & 28.71428 & 165.8571 & 44 & 0.261404 \\
H & 19.71428 & 170.8571 & 46 & 0.267459 \\
I & 21.71428 & 172.8571 & 7 & \\
J & 24.71428 & 161.8571 & 28 & 0.171012 \\
\hline
\end{tabular}

TABLE 10. Outcome of IO CRS model.

\begin{tabular}{|c|c|c|c|c|c|c|c|c|c|c|}
\hline \multirow[b]{2}{*}{ Variable } & \multicolumn{2}{|c|}{$\mathrm{C}$} & \multicolumn{2}{|c|}{$\mathrm{E}$} & \multicolumn{2}{|c|}{ G } & \multicolumn{2}{|c|}{$\mathrm{H}$} & \multicolumn{2}{|c|}{$\mathrm{J}$} \\
\hline & Value & $\begin{array}{l}\text { Reduced } \\
\text { cost }\end{array}$ & Value & $\begin{array}{l}\text { Reduced } \\
\text { cost }\end{array}$ & Value & $\begin{array}{l}\text { Reduced } \\
\text { cost }\end{array}$ & Value & $\begin{array}{l}\text { Reduced } \\
\text { cost }\end{array}$ & Value & $\begin{array}{l}\text { Reduced } \\
\text { cost }\end{array}$ \\
\hline$T$ & 0.375 & 0.000 & 1.000 & 0.000 & 0.985 & 0.000 & 1.000 & 0.000 & 0.643 & 0.000 \\
\hline$S_{1}$ & 0.000 & 0.060 & 0.000 & 0.000 & 9.437 & 0.000 & 0.000 & 0.000 & 3.880 & 0.000 \\
\hline$S_{2}$ & 16.125 & 0.000 & 0.000 & 0.005 & 0.000 & 0.005 & 0.000 & 0.005 & 0.000 & 0.005 \\
\hline$S_{3}$ & 0.000 & 0.029 & 0.000 & 0.019 & 0.000 & 0.021 & 0.000 & 0.021 & 0.000 & 0.022 \\
\hline$L_{1}$ & 0.000 & 0.882 & 0.000 & 0.133 & 0.000 & 0.166 & 0.000 & 0.163 & 0.000 & 0.171 \\
\hline$L_{2}$ & 0.000 & 1.718 & 0.000 & 0.880 & 0.000 & 1.039 & 0.000 & 1.019 & 0.000 & 1.069 \\
\hline$L_{3}$ & 0.000 & 0.641 & 0.000 & 0.595 & 0.000 & 0.695 & 0.000 & 0.681 & 0.000 & 0.715 \\
\hline$L_{4}$ & 0.000 & 0.368 & 0.000 & 0.229 & 0.000 & 0.270 & 0.000 & 0.264 & 0.000 & 0.277 \\
\hline$L_{5}$ & 0.000 & 0.000 & 1.000 & 0.000 & 0.000 & 0.000 & 0.000 & 0.000 & 0.528 & 0.000 \\
\hline$L_{6}$ & 0.000 & 1.614 & 0.000 & 0.838 & 0.000 & 0.989 & 0.000 & 0.970 & 0.000 & 1.017 \\
\hline$L_{7}$ & 0.000 & 0.605 & 0.000 & 0.013 & 0.000 & 0.024 & 0.000 & 0.024 & 0.000 & 0.024 \\
\hline$L_{8}$ & 0.261 & 0.000 & 0.000 & 0.000 & 0.957 & 0.000 & 1.000 & 0.000 & 0.000 & 0.000 \\
\hline$L_{9}$ & 0.000 & 1.291 & 0.000 & 0.746 & 0.000 & 0.879 & 0.000 & 0.861 & 0.000 & 0.904 \\
\hline$L_{10}$ & 0.000 & 0.835 & 0.000 & 0.295 & 0.000 & 0.352 & 0.000 & 0.345 & 0.000 & 0.361 \\
\hline Row & $\begin{array}{l}\text { Slack or } \\
\text { Surplus }\end{array}$ & $\begin{array}{l}\text { Dual } \\
\text { price }\end{array}$ & $\begin{array}{l}\text { Slack or } \\
\text { Surplus }\end{array}$ & $\begin{array}{l}\text { Dual } \\
\text { price }\end{array}$ & $\begin{array}{l}\text { Slack or } \\
\text { Surplus }\end{array}$ & $\begin{array}{l}\text { Dual } \\
\text { price }\end{array}$ & $\begin{array}{l}\text { Slack or } \\
\text { Surplus }\end{array}$ & $\begin{array}{l}\text { Dual } \\
\text { price }\end{array}$ & $\begin{array}{l}\text { Slack or } \\
\text { Surplus }\end{array}$ & $\begin{array}{l}\text { Dual } \\
\text { price }\end{array}$ \\
\hline 1.000 & 0.359 & -1.000 & 1.000 & -1.000 & 0.976 & -1.000 & 1.000 & -1.000 & 0.639 & -1.000 \\
\hline 2.000 & 0.000 & 0.061 & 0.000 & 0.000 & 0.000 & 0.001 & 0.000 & 0.001 & 0.000 & 0.001 \\
\hline 3.000 & 0.000 & 0.001 & 0.000 & 0.005 & 0.000 & 0.006 & 0.000 & 0.006 & 0.000 & 0.006 \\
\hline 4.000 & 0.000 & -0.030 & 0.000 & -0.019 & 0.000 & -0.022 & 0.000 & -0.022 & 0.000 & -0.023 \\
\hline
\end{tabular}

data set which can endure through any CRS model (Tab. 9). The last column of Table 9 confirms that the slopes pertaining to the CRS efficient DMUs were larger than the remaining VRS efficient DMUs. Finally, the outcome of the Input oriented CRS model on this data is as per the notion depicted before. E \& H are the only candidates which could become CRS efficient DMUs. Even though attaining a VRS efficient status, C, G and J stayed as CRS inefficient members (Tab. 10).

\subsection{Validation of the new origin using the model of Sahoo et al. [31]}

The Multiplier model prescribed by Sahoo et al. [31] when applied on both E \& H (which were termed as CRS efficient) same output (mentioned in Tab. 11). Using the similar steps referred in Section 4.1, two new 
TABLE 11. Outputs of the RTS model of Sahoo et al. [31].

\begin{tabular}{lllll}
\hline \hline & \multicolumn{3}{l}{} & E \\
\cline { 2 - 5 } Variable & Value & Reduced cost & Value & Reduced cost \\
\hline$Z$ & 0 & 1 & 0 & 1 \\
$L_{1}$ & 0.826087 & 0 & 0.826087 & 0 \\
$L_{2}$ & 0.173913 & 0 & 0.173913 & 0 \\
$L_{4}$ & 62.65217 & 0 & 62.65217 & 0 \\
$L_{3}$ & 1 & 0 & 1 & 0 \\
$L_{5}$ & 18 & 0 & 18 & 0 \\
\hline Row & Slack or Surplus & Dual price & Slack or Surplus & Dual price \\
\hline 1 & 0 & 0 & 0 & 0 \\
2 & 0 & 0 & 0 & 0 \\
3 & 0 & 0 & 0 & 0 \\
4 & 0 & 0 & 0 & 0 \\
5 & 16.08696 & 0 & 16.08696 & 0 \\
6 & 51 & 0 & 51 & 0 \\
7 & 27.47826 & 0 & 27.47826 & 0 \\
8 & 12.21739 & 0 & 12.21739 & 0 \\
9 & 0 & 0 & 0 & 0 \\
10 & 48.26087 & 0 & 48.26087 & 0 \\
11 & 8.565217 & 0 & 8.565217 & 0 \\
12 & 0 & 0 & 0 & 0 \\
13 & 41 & 0 & 41 & 0 \\
14 & 20.56522 & 0 & 20.56522 & 0 \\
15 & 55.08696 & 0 & 55.08696 & 0 \\
16 & 52 & 0 & 52 & 0 \\
17 & 39.47826 & 0 & 39.47826 & 0 \\
18 & 48.21739 & 0 & 48.21739 & 0 \\
19 & 53 & 0 & 53 & 0 \\
20 & 48.26087 & 0 & 48.26087 & 0 \\
21 & 52.56522 & 0 & 52.56522 & 0 \\
22 & 46 & 0 & 46 & 0 \\
23 & 48 & 0 & 48 & 0 \\
24 & 48.56522 & 0 & 48.56522 & 0 \\
25 & 39 & 0 & 39 & 0 \\
26 & 1 & 0 & 1 & 0 \\
27 & 12 & 0 & 12 & 0 \\
28 & 36 & 0 & 36 & 0 \\
29 & 53 & 0 & 53 & 0 \\
30 & 0 & 0 & 0 & 0 \\
31 & 44 & 0 & 44 & 0 \\
32 & 46 & 0 & 46 & 0 \\
33 & 7 & 0 & 28 & \\
34 & 28 & & & \\
\hline & & 0 & 0 & \\
\hline
\end{tabular}

equations are obtained:

$$
0.827 x_{1}+0.174 x_{2}+62.66=y+18 \text {. }
$$

The new origin derived from the proposed model $(-40.714,-166.857,-18)$ obeys these two equations as well. Hence, the plane defined by MPSS contains the existing origin. 


\section{Conclusion}

The entire study hovers around two points. Firstly, it resolves that the DMU displaying the CRS is truly a Pseudo CRS Efficient member. In other words, it is situated on the CRS frontier drawn from the new origin defined by the model. Secondly, it proves that the true CRS can only exist when the input output vector remains either positive or negative. But, in other two cases the CRS frontier is to be initiated from a point other than the real origin. Hence, it can be stated that CRS frontier always exists but depending on the nature of the data the origin needs to be shifted.

Acknowledgements. I shall remain indebted to Prof. Emrouznejad Ali (Aston University, UK) for his unconditional support.

\section{REFERENCES}

[1] A.I. Ali and L.M. Seiford, Translation invariance in data envelopment analysis. Oper. Res. Lett. 9 (1990) $403-405$.

[2] M. Allahyar and M.R. Malkhalifeh, Negative data in data envelopment analysis: efficiency analysis and estimating return to scale. Comput. Ind. Eng. 82 (2015) 78-81.

[3] G.R. Amin and S.A. Muharram, A new inverse data envelopment analysis model for mergers with negative data. Inst. Math. App. J. Manage. Math. 29 (2018) 137-149.

[4] J. Aparicio and J.T. Pastor, Closest targets and strong monotonicity on the strongly efficient frontier in DEA. Omega 44 (2014) 51-57.

[5] R.D. Banker, A. Charnes and W.W. Cooper, Some models for estimating technical and scale inefficiencies in data envelopment analysis. Manage. Sci. 30 (1984) 1078-1092.

[6] P.L. Brockett, A. Charnes, W.W. Cooper, Z.M. Huang and D.B. Sun, Data transformation in DEA cone ratio envelopment approaches for monitoring bank performances. Eur. J. Oper. Res. 98 (1997) 250-268.

[7] R.G. Chambers, Y. Chung and R. Fare, Benefit and distance functions. J. Econ. Theory 70 (1996) $407-419$.

[8] R.G. Chambers, Y. Chung and R. Fare, Profit, directional distance functions, and Nerlovian efficiency. J. Optim. Theory App. 98 (1998) 351-364.

[9] A. Charnes, W.W. Cooper and E. Rhodes, Measuring the efficiency of decision-making units. Eur. J. Oper. Res. 2 (1978) $429-444$.

[10] A. Charnes, W.W. Cooper, Q.L. Wei and Z.M. Huang, Cone ratio data envelopment analysis and multi-objective programming. Int. J. Syst. Sci. 20 (1989) 1099-1118.

[11] G. Cheng, P. Zervopoulos and Z. Qian, A variant of radial measure capable of dealing with negative inputs and outputs in data envelopment analysis. Eur. J. Oper. Res. 225 (2013) 100-105.

[12] W.W. Cooper, M.L. Seiford and K. Tone, Data Envelopment Analysis: A Comprehensive Text with Models, Applications, References and DEA-Solver Software. Kluwer Academic Publishers, New York, NY 2 (2011) 42-43.

[13] A. Emrouznejad and A.L. Anouze, A semi-oriented radial measure for measuring the efficiency of decision making units with negative data, using DEA. Eur. J. Oper. Res. 200 (2010) 297-304.

[14] R. Fare and S. Grasskoff, Theory and application of directional distance functions. J. Prod. Anal. 13 (2000) $93-103$.

[15] R. Fare, S. Grasskoff and C.A.K. Lovell, The Measurement of Efficiency of Production. Kluwer Nijhoff Publishing, Boston, MA (1985).

[16] R. Fare, S. Grasskoff, C.A.K. Lovell and C. Pasurka, Multilateral productivity comparison when some outputs are undesirable: a non-parametric approach. Rev. Econ. Stat. 71 (1989) 90-98.

[17] R. Fare, S. Grasskoff and C.A.K. Lovell, Production Frontiers. Cambridge University Press, Cambridge, UK (1994).

[18] M.J. Farrell, The measurement of productive efficiency. J. R. Stat. Soc. Ser.-A 120 (1957) 253-281.

[19] M. Halme, T. Pro and M. Koivu, Dealing with interval-scale data in data envelopment analysis. Eur. J. Oper. Res. 137 (2002) $22-27$.

[20] S.N. Hwang, C. Chen, Y. Chen, H.S. Lee and P.D. Shen, Sustainable design performance evaluation with application in automobile industry: focusing on the inefficiency by undesirable factors. Omega 41 (2013) 553-558.

[21] A. Koutsoyiannis, Modern Microeconomics, 2nd edition. Macmillan Press Ltd, New York, NY (1979) 76-82.

[22] R. Lin and Z. Chen, A directional distance based super-efficiency DEA model handling negative data. J. Oper. Res. Soc. 68 (2017) 1312-1322.

[23] D.G. Luenberger, Benefit functions and duality. J. Math. Econ. 21 (1992) 461-481.

[24] R.K. Matin and R. Azizi, Modified semi-oriented Radial Measure for measuring the efficiency of DMUs. In: With 3rd Operation, Research Conference (2010).

[25] M. Mohammadpour, F. Hosseinzadeh-Lotfi and G.R. Jahanshahloo, An extended slacks-based measure model for data envelopment analysis with negative data. J. Oper. Res. Soc. 66 (2015) 1206-1211.

[26] J.T. Pastor, Efficiency of bank branches through DEA: the attracting of liabilities. Working Paper, Universidad de Alicante, Alicante (1993). 
[27] J.T. Pastor, Translation invariance in data envelopment analysis: a generalization. Ann. Oper. Res. 66 (1996) 93-102.

[28] J.T. Pastor and J.L. Ruiz, Variable with negative values in DEA, edited by J. Zhu and W.D. Cook. In: Modeling Data Irregularities and Structural Complexities in Data Envelopment Analysis. Springer, Boston, MA (2007) 63-84.

[29] M.C.A.S. Portela, E. Thanassoulis and G. Simpson, Negative data in DEA: a directional distance approach applied to bank branches. J. Oper. Res. Soc. 55 (2004) 1111-1121.

[30] S.C. Ray, Data Envelopment Analysis Theory \& Techniques for Economics \& Operation Research. Cambridge University Press, New York, NY (2004).

[31] B.K. Sahoo, M. Khoveyni, R. Eslami and P. Chaudhury, Returns to scale and most productive scale size in DEA with negative data. Eur. J. Oper. Res. 255 (2016) 545-558.

[32] H. Scheel, Undesirable outputs in efficiency valuations. Eur. J. Oper. Res. 132 (2001) 400-410.

[33] L.M. Seiford, A bibliography of data envelopment analysis. Working Paper, Department of Industrial Engineering and Operations Research, University of Amherst, MA (1989).

[34] J.A. Sharp, W.B. Lio and W. Meng, A modified slack-based measure model for data envelopment analysis with "natural" negative outputs and input. J. Oper. Res. Soc. 57 (2006) 1-6.

[35] R.W. Shephard, Cost and Production Functions. Princeton University Press, Princeton, NJ (1953).

[36] D.A. Starrett, Measuring returns to scale in the aggregate, and the scale effect of public goods. Econometrica 45 (1977) 1439-1455.

[37] R.M. Thrall, The lack of invariance of optimal dual solutions under translation. Ann. Oper. Res. 66 (1996) $103-108$.

[38] F. Wei, J. Song, C. Jiao and F. Yang, A modified slacks-based ranking method handling negative data in data envelopment analysis. Willey Expert Syst. 36 (2019) e12329. 